Travaux du Muséum National d'Histoire Naturelle «Grigore Antipa»
Vol. 60 (2)

pp. $425-434$

\title{
A New Species of the Genus Anamixis (Amphipoda: Leucothoidae) from the Gulf of California, Mexico
}

\author{
Manuel ORTIZ, ${ }^{1,}$, Norberto CAPETILLO², Ignacio WINFIELD ${ }^{1}$
}

\begin{abstract}
${ }^{1}$ Laboratorio de Crustáceos, Facultad de Estudios Superiores Iztacala, Universidad Nacional Autónoma de México. Avenida de Los Barrios, No. 1, Los Reyes Iztacala, Tlalnepantla, Estado de México;

${ }^{2}$ Federación de Sociedades Cooperativas Pesqueras Zona Centro, BCS, SC de RL de CV (FEDECOOP Zona Centro BC Sur), México.

*corresponding author, e-mail: ortiztouzet@yahoo.com
\end{abstract}

Received: August 25, 2017; Accepted: November 6, 2017; Available online: December 28, 2017; Printed: December 31, 2017

\begin{abstract}
A new species of the genus Anamixis Stebbing, 1897 is herein described. The material was obtained from a collector of puerulus larvae of spiny lobsters, anchored at Punta Coyote, Gulf of California, Mexico. The new species differs from the others, by the head with eyes devoid of ommatidia; keel subquadrate; maxilliped inner plates almost fused; accessory flagellum of one tiny article; coxa 1 vestigial a bifid anteroventrally and distal part of propodus of pereopods $3-7$ bearing an unusual small fissure. The new species is the $24^{\text {th }}$ known species, the third record in the genus from North American Pacific, as well as the first record of the genus for Mexican Pacific.
\end{abstract}

Key words: Amphipoda, new species, Gulf of California, Mexico

\section{INTRODUCTION}

Members of the family Leucothoidae Dana, 1852 are usually collected associated with algae, seagrasses, sponges, coral rubble, bivalve mollusks and ascidian hosts, but also with anthozoan, crustacean, polychaetes and some anomuran crabs.

The taxonomy of the family was adequately understood after the description of the transformation of the Leucothoides morph into the Anamixis morph (Thomas \& Barnard, 1983).

So far, it is composed by the clades anamixis including genera Anamixis Stebbing, 1897; Nepanamixis Thomas, 1997 and Paranamixis (Schellenberg, 1938), as well as, a leucothoid clade including genera Leucothoe Leach, 1814 and Paraleucothoe Stebbing, 1889) (White, 2011).

The diagnosis of the anamixis clade has reduced mouthparts; coxa 1 reduced; gnathopod 2 carpus elongate; extreme sexual dimorphism to adult males; juvenile morphology dissimilar (White, 2011).

The 23 species of the marine genus Anamixis has a wide distribution mainly in the shallow waters of the Indo-Pacific, the Red Sea, the Caribbean Sea, Gulf of Mexico, Western Atlantic, Gulf of California, the South China Sea, the Sea of Japan, and the Andaman Sea. They were collected in association with algae, sea grasses, sponges, coral rubbles or live corals (White, 2011; White \& Reimer, 2012; White \& Krapp-Schickel, 2017; WoRMS, 2017).

This paper presents the descriptions of a new Anamixis species from the Gulf of Califonia, Mexican Pacific. 


\section{MATERIAL AND METHODS}

The specimen was caught from a collector of puerulus larvae of spiny lobsters (Phillips, 1972), as result of an ongoing research, which is carrying out by FEDECOOP Zona Centro BC Sur, at Corredor Marino San Cosme-Punta Coyote, Gulf of California.

The new species was selected from an invertebrate sample, preserved in alcohol and sent to the Laboratory of Crustacean, Facultad de Estudios Superiores Iztacala, UNAM, for posterior study. Dissections and figures were made with the aid of a Motic stereomicroscope with adapted clear camera. Figures were inked with the Corel Draw X-4 program. The terminology used in present paper follows White, 2011; White \& Reimer, 2012 and White \& Krapp-Schickel, 2017). The taxonomic procedure follows Lowry \& Myers (2017).

\section{RESULTS}

\section{SYSTEMATICS}

Subphylum Crustacea Brünnich, 1772

Superclass Multicrustacea Regier, Schultz, Zwick, Hussey,

Ball, Wetzer, Martin and Cunningham, 2010

Class Malacostraca Latreille, 1802

Subclass Eumalacostraca Grobben, 1892

Superorder Peracarida Calman, 1904

Order Amphipoda Latreille, 1816

Suborder Amphilochidea Boeck, 1871

Infraorder Amphilochida Boeck, 1871

Parvorder Amphilochidira Boeck, 1871

Superfamily Leucothoidea Dana, 1852 (Bousfield, 1979)

Family Leucothoidae Dana, 1852

Genus Anamixis Stebbing, 1897

Anamixis coyotense sp. nov

(Figs 1-6)

Material examined: Holotype: anamorph adult male; $3 \mathrm{~mm}$; September 30, 2016; $2 \mathrm{~m}$ in depth; collected by the second author. Deposited in the Colección Nacional de Crustáceos, Instituto de Biología, Universidad Nacional Autónoma de México, CNCR 34058.

\section{Diagnosis}

Head anterodistal margin oblique; without lateral ridge; ventral keel subquadrate; maxilliped inner plates almost fused, with small cleft; accessory flagellum with one article, eye visible, devoid of ommatidia; Antenna 1 long, as long as head plus three first pereonal segments combined. Coxa 1 reduced, anteroventral corner bifid; gnathopod 1 carpus thin; palm serrate; inner face of gnathopod 2 with 1 mediofacial setal row of 9 setae above midline; propodus of pereopods 3-7 with distal fissure; epimeral plate 3 with posterodistal tooth; telson rounded apically, 1.3 times longer than wide.

\section{Description of anamorph adult male (holotype)}

Head. Longer than pereonal segment 1; anterodistal margin oblique, poorly produced; without lateral ridge; ventral keel subquadrate; eye without ommatidia, apparently not functional (Fig. 1). 
Antenna I. Length 0.3 times body length; 0.3 longer than antenna 2; as long as head plus three first pereonal segments combined; peduncle radios 1:1:1 (equals in length); accessory flagellum vestigial, 1-articulate; main flagellum 9-articulate (Fig. 1). Antenna II. Length 0.2 times body length; article 4 wider than 5, both of same length; flagellum short, 4-articulate (Fig. 1).

Keel. Sub-quadrate, anteroventral corner bifid (Fig. 2).

Maxilliped. Inner plate almost fussed, reduced, distal margin with small cleft; outer plate smooth, reduced; palp articles 2 and 3 roughly in part; article 4 elongate, slender, poorly recurved (Figs 2, 3A).

Coxae 1-4 relative widths 1.0:2.8:2.0:2.2 (Fig. 1);

Coxa I. reduced; anteroventral corner bifid (Fig. 1).

Coxa II. Smooth; $1.5 \mathrm{x}$ deeper than long; with small notch on anteroventral and posteroventral corners; rounded ventrally; facial setae absent (Fig. 1).

Coxa III. Smooth; with a small notch in posteroventral corner; subrectangular; facial setae absent (Fig. 1).

Coxa IV. Smooth; with small notch in anteroventral corner; subquadrate; without forming posterior lobe; facial setae absent (Fig. 1).

Coxa V. Smooth; longer than depth; forming two ventral lobes; with 2 setae on anterior margin; 3 in posterior margin (Fig. 5C).

Coxa VI. Smooth; longer than depth; forming two ventral lobes; without setae on anterior margin; with 3 robust setae on posterior margin (Fig. 5D).

Coxa VII. Smooth; subquadrate; ventral margin slightly rounded; devoid of setae (Fig. 5E).

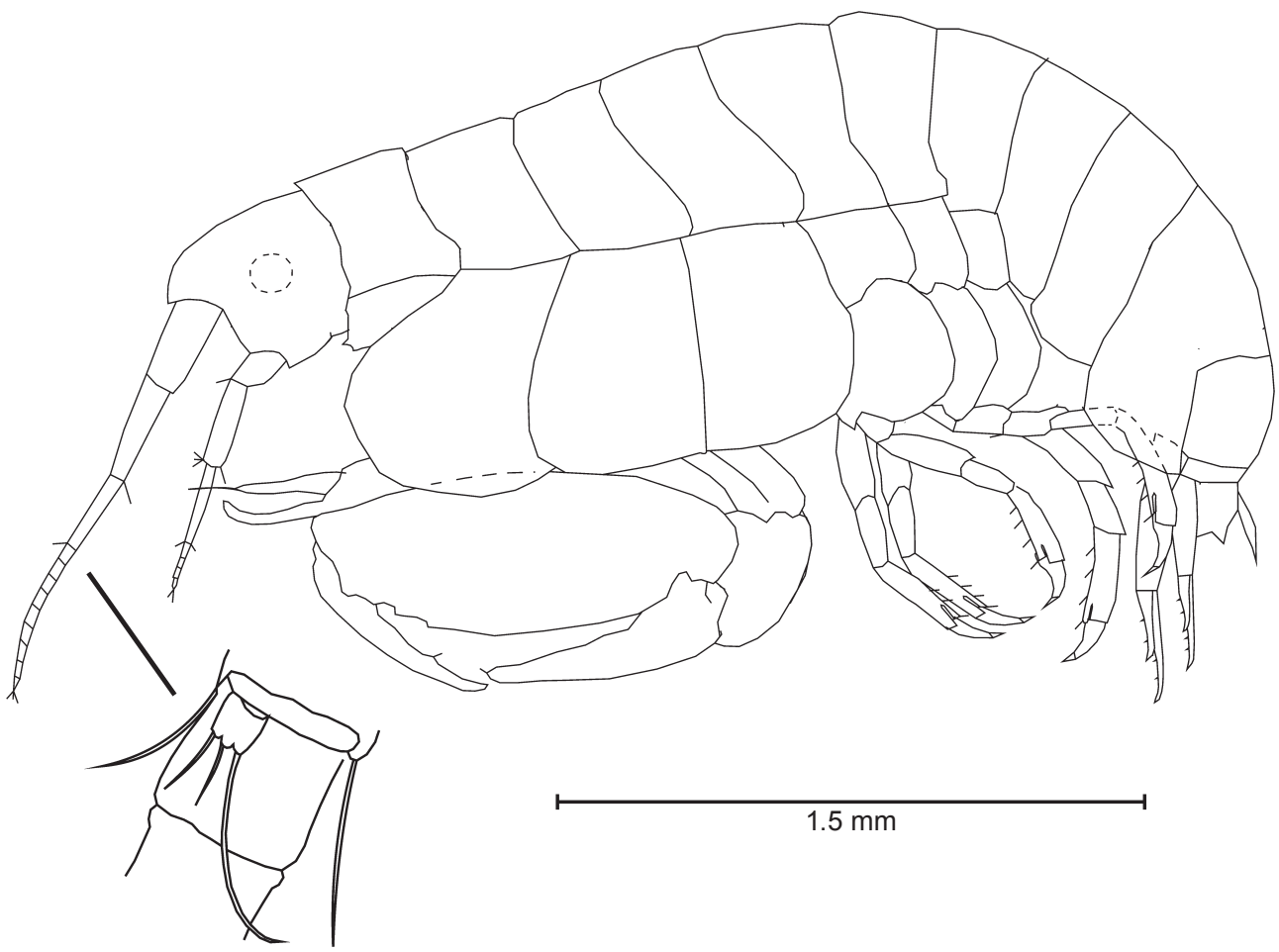

Fig. 1 - Lateral view of anamorph male holotype (accessory flagellum magnified). 


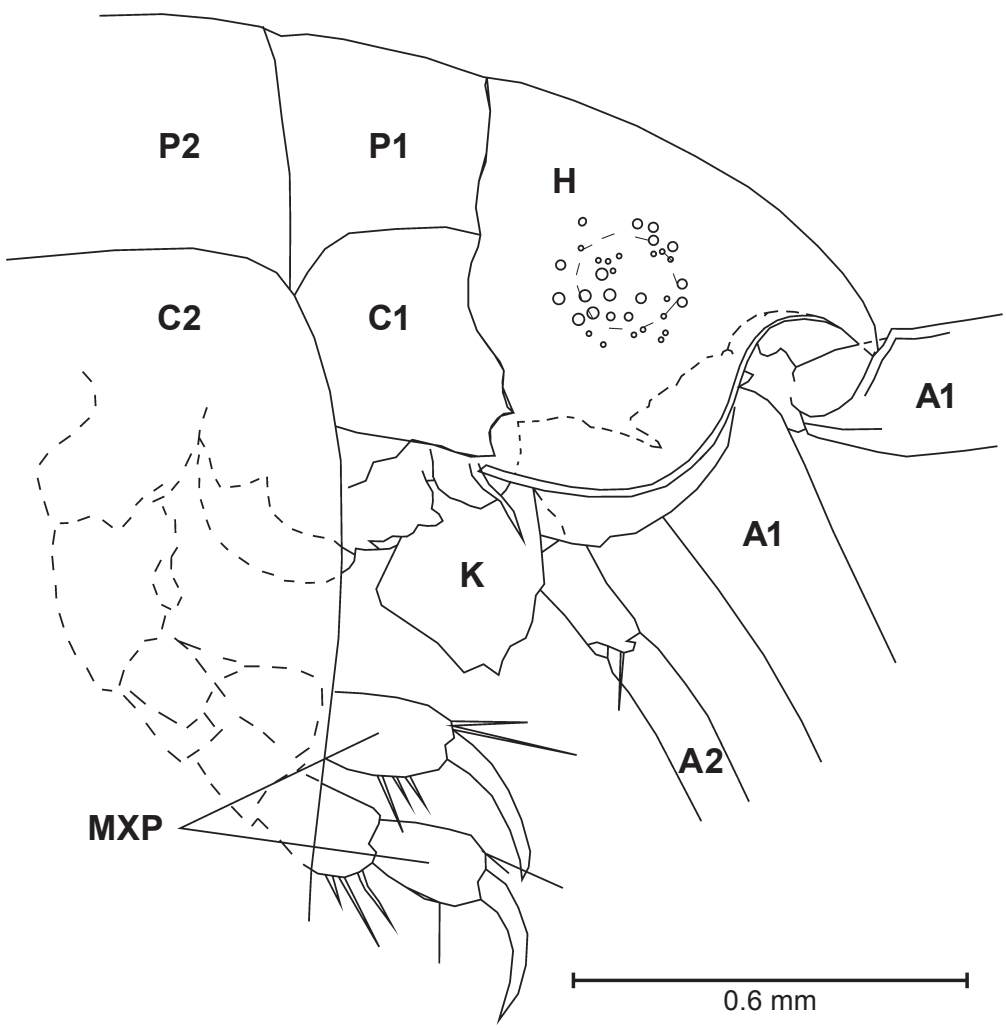

Fig. 2 - Lateral view of anterior body: A1, antenna I; A2, antenna II; C1, coxa I; C2, coxa II; H, head; K, keel; MXP, maxilliped; P1, pereonal segment I; P2, pereonal segment II.

Gnathopod I. Carpochelate; basis linear, constricted basally, as long as carpus; basis, ischium, carpus and propodus bare; carpal lobe curved distally; carpal apex bare; propodus gently curved upward; posterior margin minutely serrate; distal seta curved, very slender, extending beyond carpus (Fig. 3B).

Gnathopod II. Carpochelate; basis as long as propodus, tapering distally, with mid-distal tubercle; and 4 tiny setae on anterior margin; posterior margin bare; carpus slightly curved upward; ischium and merus bare; carpal lobe curved distally; 2 times longer than wide; facial face covered with setae; propodus 2.1-2.2 times longer than wide; anterodistal margin with one small and two big teeth, on distal half; with 1 mediofacial setal row of 9 setae above midline, reaching $0.5 \mathrm{x}$ propodus length; dactylus curved backward, reaching 0.5 of propodus length; with 3 small teeth on posterior margin (Fig. 4).

Pereopods III-IV bases width-length ratios 1:3.6, 1:4.

Pereopod III. Basis and ischium bare; basis as long as merus and carpus combined; merus $0.9 \mathrm{x}$ carpus length; forming small antero-distal lobe with terminal seta; carpus $0.8 \times$ propodus length; with antero distal seta; propodus with distal fissure; with 3 robust setae on posterior margin; dactylus short, 0.3 x propodus length, curved, with nail (Fig. 5A). 
Pereopod IV. Basis and ischium bare; basis as long as carpus and propodus combined; merus and carpus forming small antero-distal lobe, with terminal seta; propodus with distal fissure, with 3 robust setae on posterior margin; dactylus short, $0.3 \mathrm{x}$ propodus length, curved with nail (Fig. 5B).

Pereopods $V-V I I$ bases width-length ratios 1:1.2, 1:1, 1:1 (Fig. 5).

Pereopod $V$. Basis forming a wide posterior lobe; anterior margin with 5 setae; merus forming posterior lobe, with one distal robust seta; with 4 setae on anterior margin; carpus with 3 robust setae on anterior margin; with 1 posterodistal robust seta; propodus $2 \mathrm{x}$ carpus length, with 5 robust setae on anterior margin; with distal fissure; dactylus short, $0.3 \mathrm{x}$ propodus length, curved, with nail (Fig. 5C).

Pereopod VI. Basis as long as propodus, with posterior lobe tapering distally; with 2 teeth on posterior margin; merus with small posterior lobe with long distal seta; with 3 robust setae on anterior margin; carpus 0.7 x propodus length; with 5

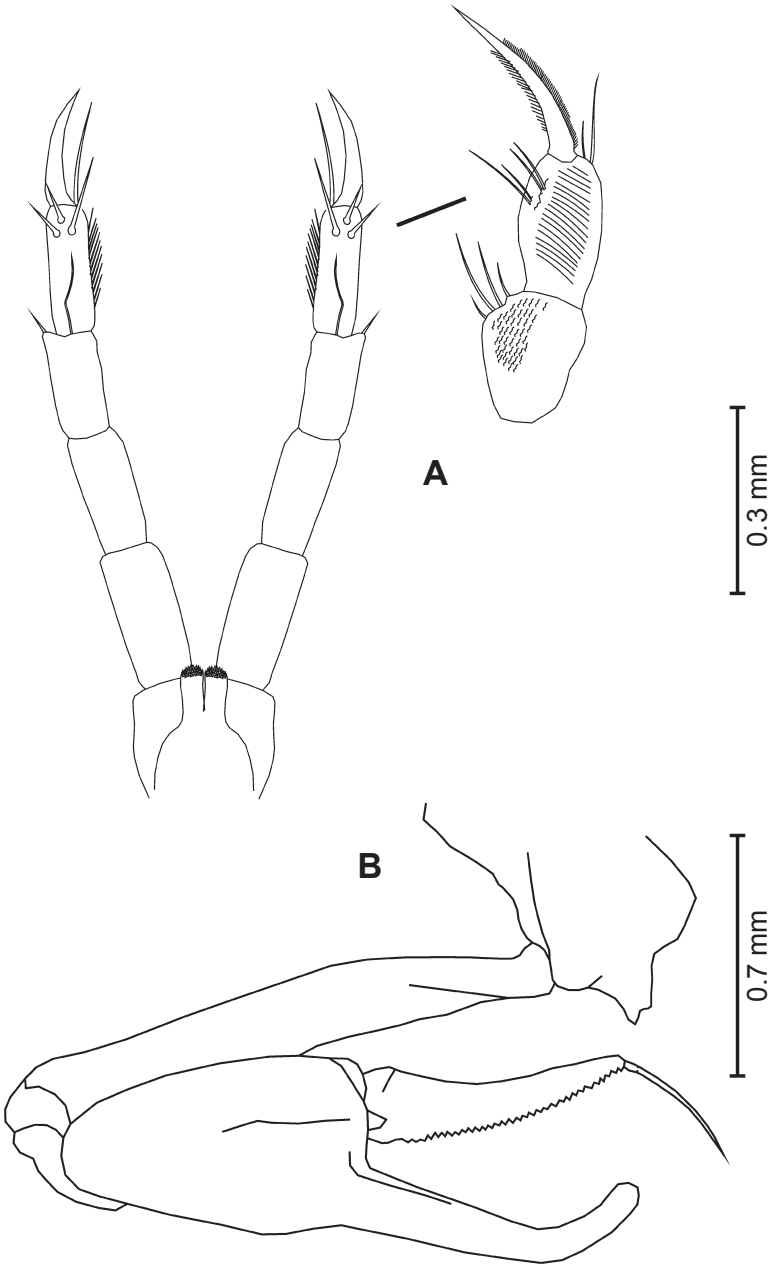

Fig. 3 - General view of maxilliped and gnathopod I; A, ventral view of maxilliped (articles 2-4 magnified); B, lateral view of gnathopod I. 


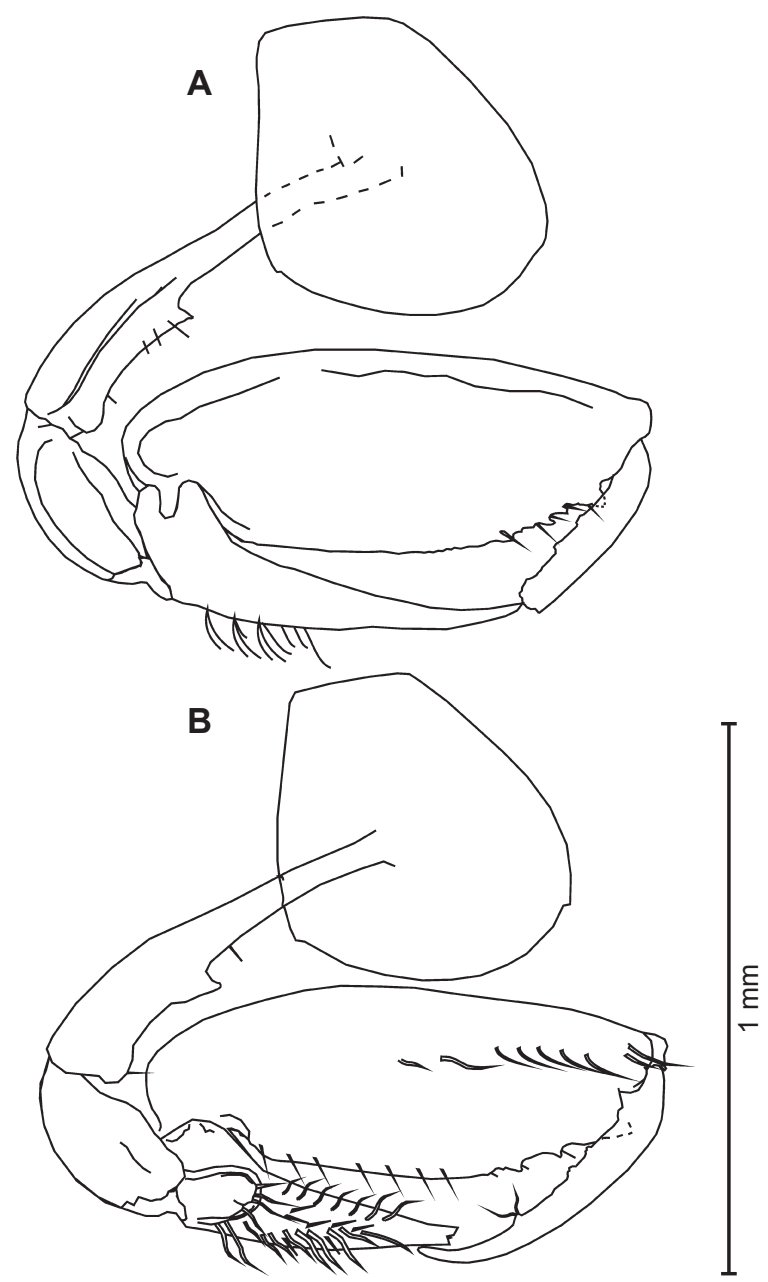

Fig. 4 - Gnathopod II; A, lateral view right gnathopod; B, facial view of left gnathopod.

robust setae on anterior margin; propodus with 5 robust setae on anterior margin; with distal fissure; dactylus short, $0.2 \mathrm{x}$ propodus length, curved, with nail (Fig. 5D).

Pereopod VII. Basis as long as propodus, with posterior lobe tapering distally, with finely crenulated posterior margin; anterior margin with 6 robust setae; merus forming a discrete posterior lobe, devoid of distal setae; carpus $0.5 \mathrm{x}$ propodus length, with 2 anterodistal robust setae; propodus with 4 robust setae on anterior margin; posterior margin smooth; with distal fissure; dactylus short, $0.3 \mathrm{x}$ propodus length, curved, with nail (Fig. 5E).

Uropods 1-2 relative lengths 1.0: 0.7 .

Uropod I. $1.3 \mathrm{x}$ length uropod 2; peduncle $0.8 \mathrm{x}$ inner ramus length; outer ramus $0.7 \mathrm{x}$ inner ramus length; peduncle inner margin with 4 robust setae; outer ramus with 3 robust setae; inner ramus with 3 (Fig. 6A). 
Uropod II. Peduncle as long as outer ramus; with a distal robust seta; outer ramus with 3 robust setae in distal half; inner ramus $0.7 \mathrm{x}$ outer ramus length; with 2 setae in distal half of inner margin (Fig. 6B).

Uropod III missing.

Telson. $1.3 \mathrm{x}$ longer than wide, apex rounded; bare; almost flat in lateral view (Fig. 6C, D)

Epimera. Epimera 1-3 bare; epimera 1-2 rounded ventrally; epimera 2-3 with reinforced margin at anteroventral corner; epimeron 3 with posteroventral tooth (Fig. 6D).

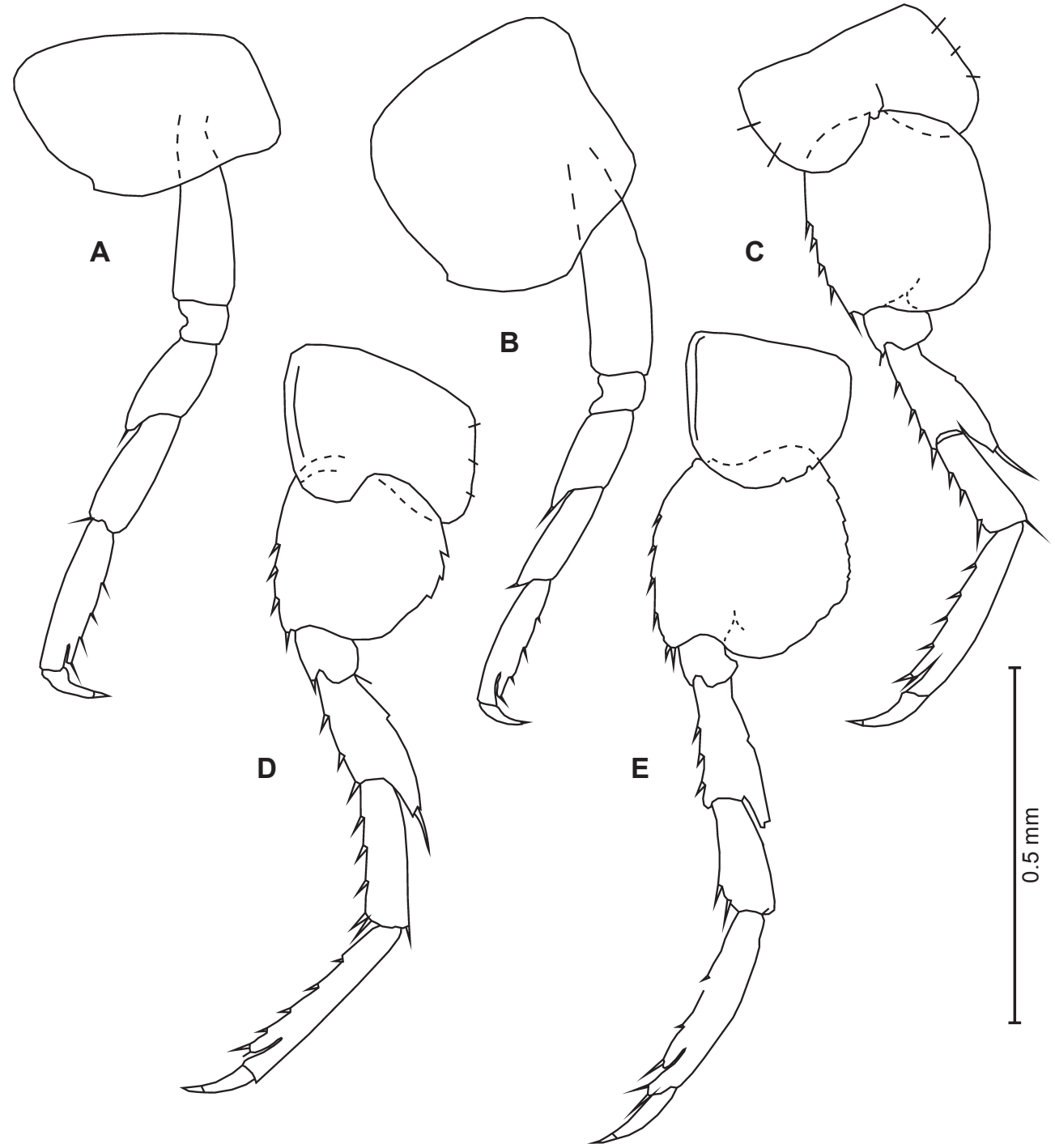

Fig. 5 - Pereopods; A, pereopod III; B, pereopod IV; C, pereopod V; D, pereopod VI; E, pereopod VII. 
unknown.

Leucomorph male and female, and anamorph female of the new species are

\section{Remarks}

From the 23 Anamixis species known till present, Anamixis coyotense sp. nov. appears most closely related to A. cavatura Thomas, 1997 . Both species share the head with the anterodistal margin oblique; lateral ridge absent; almost smooth anterior margin of ventral keel; article 6 of gnathopod 2 not elongate, 2.1-2.2 times longer than wide; inner margin of dactyl tuberculate; gnathopod 1, coxa, distally bifid; carpus, upturned distally, inner margin lacking serrations; propodus apex not reaching apex of carpus; inner margin unevenly serrate; gnathopod 2, coxa larger than 2 or 3 , rounded ventrally; carpus recurved; propodus with 3 teeth; dactyl slightly recurved, with 2-3 tubercles on inner margin. On the other hand, $A$. coyotense sp. nov.

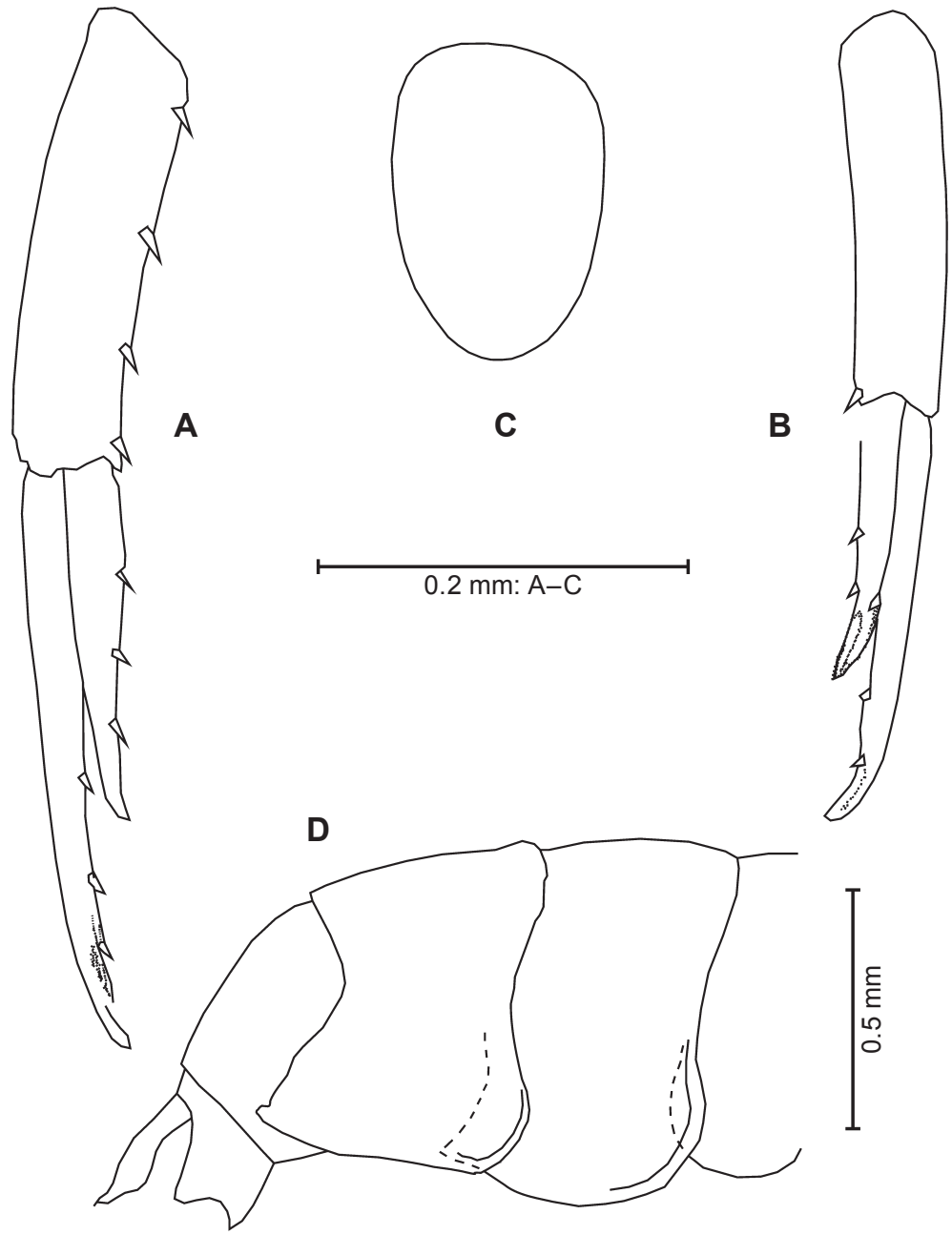

Fig. 6 - Uropods, metasoma and telson: A, uropod I; B, uropod II, C, dorsal view of telson; D, lateral view of urosoma showing the epimera and telson. 
differs from A. cavatura, by having no eyes with ommatidia (present in A. cavatura); gnathopod 1 apex of carpus bare (with 1 seta in $A$. cavatura); posteroventral corner of epimera 3 with tooth (missing in A. cavatura) and propodus of pereopods 3-7 with distal fissure (absent in A. cavatura). Also, A. coyotense sp. nov., comes from the North American Western Pacific, and the general distribution of A. cavatura is in the Western Atlantic Ocean (White, 2011).

Also, the only two known species of the genus with a Western American distribution are A. pacifica (Barnard, 1955) and A. yarrega Barnard, 1974. So, A. coyotense sp. nov., differs from $A$. pacifica by eye devoid of ommatidia (with ommatidia in A. pacifica); head anterodistal margin oblique; (transverse in A. pacifica); antenna 1 peduncle ratio 1: 1: 1 (14: 10; 7 in $A$. pacifica); gnathopod 1 propodus apical spine very extended beyond carpus (scarcely extending beyond carpus in $A$. pacifica); propodus on pereopods 3-7 with distal fissure (absent in A. pacifica).

It differs from $A$. yarrega by eye without ommatidia in the new species (present in A. yarrega); coxa 1 bifid anterodistally (rounded in A. yarrega); chela of gnathopod 1 curved (straight in $A$. yarrega); antenna 1 accessory flagellum 1-articulated (4-articulated in A. yarrega); propodus on pereopods 3-7 with distal fissure (absent in $A$. yarrega).

Likewise, A. coyotense sp. nov. differs from all the other species in the genus by wearing a distal fissure on propodus of pereopods 3-7, aspect never seen before in members of genus Anamixis.

Finally, Anamixis coyotense $\mathrm{n}$. sp., is the $24^{\text {th }}$ known species of the genus, and the third recorded for Western North America, and first recorded for the Mexican Pacific.

Etymology. The holotype anamorph male was named A. coyotensis, because of the type locality, Punta Coyote, at Corredor Marino San Cosme-Punta Coyote, Baja California Sur, México.

\section{ACKNOWLEDGMENTS}

The second author thanks the technicians of FEDECOOP Zona Centro, Daniel Vazquez, Hideki Yoshida and Carlos Godinez, as well as to Armando Vega and Fatima Gisela Medina of the Centro Regional de Investigaciones Pesqueras (CRIP), Baja California Sur, for the collection of the samples. A special recognition to the SAGARPA-CONAPESCA for the financial support offered for the execution of the investigation project "Evaluaciòn de las Zonas de Refugio Pesquero en el Corredor San Cosme-Punta Coyote, Golfo de California, Baja California Sur, México".

\section{REFERENCES}

LOWRY, J.K., A.A. MYERS (2017) A Phylogeny and Classification of the Amphipoda with the stablishment of the new order Ingolfiellida (Crustacea: Peracarida). Zootaxa, Monograph, 4265(1): 001-089.

PHILLIPS, B.F. (1972) A semi-quantitative collector of the puerulus larva of the western rock lobster Panulirus longipes cygnus George (Decapoda, Palinuridea). Crustaceana, 22: 147-154.

SEREJO, C.S. (1996) Podocerus fissipes n. sp., a new species of sponge-dwelling amphipod (Amphipoda, Podoceridae) from Brazilian Coast. Nauplius, Revista da Sociedade Brasileira de Carcinología, 3: 49-57.

THOMAS, J. D., J.L. BARNARD (1983) Transformation on the Leucothoides morph, into the Anamixis morph (Amphipoda). Journal of Crustacean Biology, 3: 154-157.

WHITE, K.N. (2011) A taxonomic review of the Leucothoidae (Crustacea: Amphipoda), Zootaxa, Monograph, 3078: 1-113.

WHITE, K., T. KRAPP-SCHICKEL (2017) Red Sea Leucothoidae (Crustacea: Amphipoda) including new and re-described species. European Journal of Taxonomy 324: 1-40.

WHITE, K., J. REIMER (2012) Commensal Leucothoidae (Crustacea, Amphipoda) of the Ryukyu Archipelago, Japan, III: coral rubble-dwellers. Zookeys, 173: 11-50. 
WoRMS Editorial Board (2017) World Register of Marine Species. Available from http://www. marinespecies.org at VLIZ. Accessed on $28^{\text {th }}$ of July 2017. Doi, 10.14284/170. 